\title{
O HOMEM QUE SE aCHAVA NaPOleÃo: POR UMA HISTÓRIA POLÍTICA DA LOUCURA
}

\author{
The man who mistook himself for Napoleon: for a \\ political history of madness \\ Elle hombre que se creia Napoleón: por \\ uma historia politica de la loucura
}

Esther Maria de M. Arantes* Paulo Vaz**

Resenha do livro: Murat, L. (2012). O homem que se achava Napoleão: por uma história política da loucura. São Paulo: Três Estrelas. 399p.

O livro da historiadora Laure Murat, O homem que se achava Napoleão: por uma história política da loucura, surgiu pela questão "Que impacto os acontecimentos históricos têm sobre a loucura?" ou "Em que medida e sob que formas a política é matéria de delírio?” (Murat, 2012, p. 19). Não se trata só dos loucos, pois, como pergunta a autora: "Como não ser afetado pelo formidável espetáculo do fim de um mundo?” (Murat, 2012, p. 66).

O livro é o resultado de uma vasta pesquisa realizada nos registros e observaçóes médicas dos grandes asilos de alienados do departamento de Sena na França, no período compreendido entre a Revolução Francesa e a Comuna de Paris (1789 a 1871): Bicêtre (36 volumes), Salpêtrière (46 volumes) e Sainte-Anne (27 volumes), além de Charenton (54 volumes). A esse fabuloso conjunto de registros

\footnotetext{
* Pontifícia Universidade Católica do Rio de Janeiro, Rio de Janeiro, RJ, Brasil; Universidade do Estado do Rio de Janeiro, Rio de Janeiro, RJ, Brasil.

** Professor da Universidade Federal do Rio de Janeiro, Rio de Janeiro, RJ, Brasil.
} 
e observaçóes médicas, examinados como fonte principal, somaram-se outros, provenientes dos Arquivos Nacionais, dos Arquivos de Paris e dos Arquivos da Chefatura de Polícia de Paris, com os quais se cruzaram informaçóes.

A escolha de Paris como epicentro, e das datas de 1789 a 1871, respondeu a exigências históricas evidentes. Entre a Revolução e a Comuna, a França conheceu pelo menos quatro revoluçóes - revoluçóes a cada vez confiscadas, expressão da lenta agonia do princípio monárquico em paralelo ao nascimento doloroso e à instauração sempre adiada da República. Ora, num Estado tão centralizador como a França, é na capital que se tomam as principais decisóes políticas, é lá que se produzem os acontecimentos que terão as mais fortes repercussóes e onde também se erguem os três estabelecimentos especializados para os quais a maioria dos alienados seria por muito tempo enviada: Charenton, Bicêtre e Salpêtrière, a estes vem se acrescentar Sainte-Anne a partir de 1867 (Murat, 2012, p. 24-25).

Em que medida esse livro inova na relação entre psiquiatria, loucura e poder? Os conhecidos livros e artigos de Basaglia, Foucault e Goffman, dentre outros, pensavam essa relação a partir do conceito de medicalização, estimando como e até que ponto a psiquiatria era instrumento de controle social. A atribuição de loucura a indivíduos com comportamentos diferentes e pertubadores vinha substituir ou complementar as classificaçôes do Direito e da Religiáo. Embora encarcerasse os indivíduos em manicômios, a legitimidade dessa ação residia na busca do cuidado e cura. Essa classificação não afetava apenas o destino desses indivíduos perturbados e perturbadores; pelo vínculo entre loucura e desregramento do desejo, mesmo os presumidos normais temiam desejar.

Tentemos entáo destacar a singularidade do livro de Murat. De certa forma, com essa pesquisa, Murat pareceu-nos ter buscado dar continuidade a um projeto de Esquirol nunca realizado ou, pelo menos, nele se inspirado:

"A influência de nossas desgraças políticas foi tão constante", escrevia o dr. Étienne Esquirol em 1816, "que eu poderia traçar a história de nossa revolução, desde a Tomada da Bastilha até a última apariçáo de Bonaparte, a partir da história de alguns alienados cuja loucura se liga aos acontecimentos que assinalaram esse longo período de nossa história”. Esse belo projeto de uma história da França deduzida, ou decalcada, a partir dos delírios, isto é, de uma "outra cena" que recomporia à sua maneira as etapas 
da narrativa nacional, Esquirol nunca efetuou. Era pelo menos realizável? (Murat, 2012, p. 20).

Mas de quais acontecimentos se trata, nesse texto tão bem documentado, e de que estratégia metodológica se valeu a autora para contá-los? Conforme dito acima, nada menos do que a Revolução Francesa e os acontecimentos que a ela se seguiram por quase todo um século, finalizando o Antigo Regime, o que de imediato evidencia o interesse e a importância desse livro. Por outro lado, como pesquisa que privilegia o delírio dos ditos insanos internados nos asilos franceses no início da Psiquiatria - período considerado a "idade de ouro do alienismo" (Castel, 1978; Birman, 1978) -, traz à cena personagens como Pinel, Royer-Collard, Esquirol e tantos outros, ilustrando as idas e vindas desse processo em que se confundem casa de saúde e casa de detenção, loucura e oposição ao regime, como na internação do Marquês de Sade em Charenton, ou na história de Théroigne de Méricourte, ativista dos direitos das mulheres que faleceu no Salpêtrière, e o fato mesmo de ter sido a guilhotina francesa inventada pelo médico Antoine Louis e proposta pelo também médico Joseph-Ignace Guillotin como forma de igualdade na execução da pena capital, rompendo "com o sistema hierarquizado das penas sob o Antigo Regime" (Murat, 2012, p. 54).

Quanto aos arquivos, uma sua "paixão", cabe-nos repetir a declaração da autora, que, "sem planos preestabelecidos", deixou-se guiar apenas pelas centenas de registros encontrados nas pastas, o que constitui a originalidade de sua pesquisa.

à força de ouvir as palavras da loucura, de identificar suas repetiçóes e seus refrãos, de esquadrinhar os documentos - registros, mas também planos de asilos, retratos de loucos e de psiquiatras, vistas gravadas das salas de duchas... -, vem a sensação de ser penetrado, como por inoculação lenta, por um mundo à primeira vista muito estranho. Por imersão, a familiaridade com os arquivos cria uma intimidade com seu tema, que qualquer outra fonte será incapaz de oferecer. É essa capacidade evocadora do arquivo que eu quis restituir neste livro. É o prazer que senti em descobrir essas peças adormecidas que eu gostaria de compartilhar (Murat, 2012, p. 47).

Assim, essa não é uma história dos acontecimentos revolucionários como normalmente os conhecemos. Também não é uma história convencional da Psiquiatria. $\mathrm{O}$ que inicialmente chama a atenção da autora são os delírios dos loucos em torno dos acontecimentos políticos desse período, particularmente a guilho- 
tina e a chegada dos restos mortais de Napoleão à França: pessoas que afirmavam terem sido decapitadas ou na eminência de o serem, que afirmavam portarem outra cabeça, que se julgavam espionadas ou que se tomavam por Napoleáo, pela imperatriz ou o delfim. Nada, talvez, de surpreendente, considerando-se que, de março de 1793 a agosto de 1794, no período denominado Terror, cerca de dezessete mil pessoas foram executadas na guilhotina na França. Igualmente, nada de surpreendente em relação à figura forte de Napoleão. Basta lembrarmos a vinda da família real portuguesa para o Brasil, em 1808, fugindo da invasão de Portugal pelas tropas de Napoleão Bonaparte.

Nesse sentido, o que interessa à autora e o que ela busca nos arquivos desse período são as possíveis relaçôes entre os acontecimentos revolucionários e os delírios dos alienados que, ainda que alojados nos discursos dos alienistas, tentam conceber e se apropriar de eventos políticos excepcionais. No entanto, como nos adverte a própria autora, não se pode afirmar uma relaçáo simples e direta entre fato político e conteúdo delirante, o que exigirá problematizar, por exemplo, o significado da relação loucura e violência - esta última invocada por alguns alienistas em defesa da ordem monárquica.

No antigo Regime, uma menina de quinze anos enforcada pelo roubo de uma colher de prata, ou um rapaz esquartejado por ter escrito um libelo contra o rei, é algo que não provocará debates sobre a loucura do sistema judiciário sob a monarquia do direito divino. Preferirão citar o frenesi espetacular e a histeria coletiva dos massacres de setembro de 1792 para ilustrar esse tema da demência política. [...] A revolução, uma deriva patológica? Em sua maioria, os alienistas pensam assim e o repetem ao longo do século, estigmatizando a exaltação republicana e seus funestos efeitos sobre a população - pavores, siderações, delírios de perseguiçáo etc. [...] Fala-se de monomania política, depois de morbus democraticus (doença democrática), enfim de neurose revolucionária ou de paranoia reformadora, em uma escalada de termos que testemunham uma psiquiatrização crescente do político (Murat, 2012, p. 209-210).

Nem todos os alienistas postulavam uma relação direta entre revolução e loucura, sendo esse ponto de vista próprio de alienistas mais conservadores como Sylvain Eymard ou Alexandre Brierre de Boismont, que afirmava serem loucos os revolucionários e loucos bem mais perigosos que os loucos criminosos - distinção que faz crescer a importância do alienista, por ser o especialista capaz de identificar o louco dissimulado de revolucionário. Brierre de Boismont chega, 
inclusive, a afirmar que "as mulheres grávidas, sob o impacto da revolução dariam nascimento a futuros alienados" (Murat, 2012, p. 237). Outros alienistas como Esquirol preferem apenas afirmar que os acontecimentos revolucionários agem nas mentes fracas, predispostas à doença mental. Ou bem a ação política é loucura, ou aumenta o número de loucos. De todo modo, a classificação de loucura para a ação revolucionária não foi, no caso, estratégia para limitar o desejo dos indivíduos, mas esforço de reduzir a resistência ao poder. A classificação de loucura estigmatizava os movimentos sociais.

Há também quem afirme, como o alienista alemão Wilhelm Griesinger, que muitos doentes dos nervos são curados pelas revoluçóes e que as grandes comoções políticas não aumentaram a incidência de doenças mentais na França, com o que concorda Murat, a partir dos levantamentos feitos por ela nos arquivos:

a inflaçáo dos delírios políticos em tempos de revolução dá a impressão de uma epidemia de loucura devida aos distúrbios, mas as admissóes nos asilos, em realidade, não aumentaram de forma significativa. Haveria, de certo modo, uma ilusão de ótica entre as letras e os números, a amplificação (real) dos discursos e um aumento (ilusório) do número de loucos (Murat, 2012, p. 238).

Mirando o tempo presente e a partir das questóes colocadas ou insinuadas pela autora, indaga Jurandir Freire Costa, em sua Apresentação do livro:

loucura e política ainda guardam a mesma relação que tiveram na época do nascimento da psiquiatria? Hoje, ainda poderíamos verificar a estranha simbiose entre fato político e conteúdo delirante, observável nos anos de ouro do alienismo? Qual o impacto do fator político na produção dos diagnósticos psiquiátricos atuais? Enfim, a política ainda modela o imaginário social, a ponto de fornecer enredos e personagens das construçóes delirantes? (Murat, 2012, p. 9).

Lembra que o livro de Murat, "embora fiel aos grandes traços da concepção foucaultiana, promove uma ligeira inflexão na abordagem do tema” (Murat, 2012, p. 9). Nesse sentido, lembrando algumas das teses apresentadas no livro de Michel Foucault - História da loucura na idade clássica (1972/1989) - e mencionando as polêmicas ensejadas por Jacques Derrida e também por Gladys Swain em relação a esse livro, a autora afirma que sem pretender ignorar tais polêmicas preferiu, no entanto, não tomar partido e mirar apenas nos arquivos. Elizabeth 
Roudinesco, no livro Foucault: leituras da história da loucura (Roudinesco, Canguilhem, Major, \& Derrida, 1994), discute amplamente tais polêmicas.

Finalizando, no Posfácio do livro, Murat lamenta que a pesquisa que fez nos arquivos dos asilos franceses talvez hoje não fosse mais possível, na medida em que, devido a vários fatores,

os psiquiatras limitam seus comentários ao mínimo necessário, conformando-se às normas elementares do onipotente DSM-IV (Diagnostic anda Statistical Manual - Revision 4), que se impôs como a única nomenclatura de referência sobre os distúrbios mentais (Murat, 2012, p. 317).

Lembra que reduzir o delírio do louco "ao silêncio e apagar seus traços, muito mais ameaça do que protege a sociedade" (Murat, 2012, p. 319). Este tempo presente, que a autora considera "sinistro", é duramente criticado por ela.

No interior de uma sociedade que fala de "plano de saúde mental" e quer descobrir desde a escola maternal os "comportamentos delinquentes e anormais" com base em questionários de múltipla escolha, a palavra louca, com seus ensinamentos, seus desvios e sofrimentos, tem cada vez mais dificuldade de fazer-se ouvir num mundo globalizado sem tempo para escutar e manter o diálogo (Murat, 2012, p. 317).

Não em toda parte, esclarece, demonstrando algum alento. Após o discurso do então presidente francês Nicolas Sarkozy, em 2 de dezembro de 2008, no qual anunciava medidas consideradas liberticidas como

localização por GPS de pacientes internados à força, criação de unidades fechadas e de quartos de isolamento, tratamentos ambulatoriais sem consentimento, atribuição de plenos poderes ao diretor do hospital etc, um grupo se formou para protestar contra "A noite securitária", com uma petição reunindo cerca de 30 mil assinaturas (Murat, 2012, p. 318).

Entre os signatários constam psiquiatras, psicanalistas, pessoal do atendimento em saúde, dentre outros, que acreditam poder trabalhar de outro modo, mantendo "um trabalho engajado com os pacientes, buscando elaborar uma obra fecunda com as diversas expressóes da loucura” (Murat, 2012, p. 318).

Em suma, os perigos que a autora detecta em nossa cultura seriam: primeiro, o reforço da punitividade a partir da classificação de periculosidade e, 
segundo, o abandono da escuta por parte da psiquiatria. Cabe notar que o desejo de escutar a loucura foi o que deu origem ao livro.

\section{Referências}

Birman, J. (1978). A psiquiatria como discurso da moralidade. Rio de Janeiro: Edições Graal.

Castel, R. (1978). A ordem psiquiátrica: a idade de ouro do alienismo. Rio de Janeiro: Ediçóes Graal.

Foucault, M. (1989). História da loucura na idade clássica. São Paulo: Editora Perspectiva. (Trabalho original publicado em 1972)

Roudinesco, E., Canguilhem, G., Major, R., \& Derrida, J. (1994). Foucault: leituras da história da loucura. Rio de Janeiro: Relume-Dumará.

Recebido em 15 de julho de 2013 Aceito para publicação em 28 de setembro de 2013 